Арпентьева Мариям Равильевна, доктор психологических наук, доцент, член-корреспондент Российской академии естествознания (РАЕ), ведущий научный сотрудник кафедры теории и методики физического воспитания, Югорский государственный университет, г. Ханты-Мансийск, Ханты-Мансийский Автономный округ - Югра, Российская Федерация, e-mail: mariam_rav@mail.ru ORCID ID 0000-0003-3249-4941

\title{
РАЗРУШЕНИЕ УНИВЕРСИТЕТА: ОТ «ВСЕСТОРОННЕ РАЗВИТОЙ ЛИЧНОСТИ» К «РОБОТОУСТОЙЧИВОМУ СПЕЦИАЛИСТУ»
}

Arpentieva Mariam Ravilievna, grand doctor (Grand $\mathrm{PhD}$ ) of psychological Sciences, associate professor, corresponding member of the Russian academy of natural sciences (RANS), leading researcher fellow, Department at the Theory and Methods of Physical Education, Ugra State University, Khanty-Mansiysk, Khanty-Mansi Autonomous Area - Yugra,

Russian Federation, e-mail: mariam_rav@mail.ru ORCID ID 0000-0003-3249-4941

\section{THE DESTRUCTION OF THE UNIVERSITY: FROM THE "ALL-DEVELOPED PERSONALITY" TO "THE ROBOTPROOF SPECIALIST"}

\begin{abstract}
In the process of globalization, educational globalization is particularly noticeable. It moves from the upbringing and training of the person, Homo sapiens, to the "training" of the specialist, Homo habilis, and, further, to the "formation" of the consumer, Homo consumens, after which the formation of a "robot-proof" person of service or Homo officialis. The latter is naturally supplemented by Homo dominus, the formation of which can be completely different, but, in general, is not a necessity: Unification of power, cephalization of control (mondialization) actually counteract development. Digital technologies are just a small part of the process.
\end{abstract}

Key words: education, business, standardization, variable education, methodological support of education, upbringing, fundamental core, individuality, university death, competence approach, transnational corporations, robot-proof education.

Абстракт: Процесс глобализации особенно заметен в сфере образования. Он включает прерход от воспитания и обучения человека как личности, Ното sapiens $\kappa$ «обучению» специалиста Ното habilis и, кроме того, к «формированию» потребителя Ното consúmens, после которого формирование «роботоустойчивого» человека служебного или Ното оfficialis. Последний естественно дополняется подготовкой Ното dотіпиs, образование которого может быть совершенно иным, но, в общем, не является необходимостью: объединение власти, цефализачия контроля (мондиализачия) фактически противодействуют развитию. Цифровые технологии - всего лишь небольшая часть этого процесса.

Ключевые слова: образование, бизнес, стандартизачия, вариативное обучение, методическое обеспечение образования, воспитание, фундаментальное ядро, индивидуальность, 
смерть университета, компетентностный подход, транснациональные корпорации, роботоустойчивое образование.

Глобализация как феномен культуры предполагает распространение современных экономических, правовых, социологических иных теорий, в том числе средствами цифровых технологий, - в сфере их приложения к трансформации науки, искусства и образования. Глобализация направлена на трансмиссию ценностей, моделей понимания себя и мира, моделей общения стран, считающихся носителями общечеловеческой» культуры, «цивилизации» (Европа и США) в варварские страны «второго» и «третьего» миров [1; 5; 14]. Трансформация эта осуществляется на фоне последовательной деградации: переходу от ориентации на высшие достижения в сфере культуры к ориентации на достижения в сфере манипуляции людьми как средствами производства. На этом пути особенно заметные изменения претерпевает образование. Оно проходит несколько стадий, в том числе, двигается от воспитания и обучения личности, типичного Homo sapiens, сочетающего в себе Homo moralis, Homo faber и Homo ludens, к «подготовке» специалиста, Homo habilis, и, далее, к «формированию» потребителя Ното consúmens, после которого идет формирование «роботоустойчивого», способного конкурировать с роботами (!), человека служебного, Homo officialis [1; 29]. Последний естественным образом дополнен Ноmo dominus, образование которого может быть совершенно различным, но, в целом, не является необходимостью. Глобализованному миру, управляемому мондиализированным государством и ТНК (транснациональными корпорациями), группой привилегированных homo dominus, ни наука, ни образование не нужны. Унификация власти, цефализация управления (мондиализация) на самом деле противостоят развитию. Цифровые технологии на этом пути - всего лишь небольшая часть процесса, позволяющая на его срединном этапе преобразовать условия жизни «новых рабов» в достаточно жестко контролируемые. Жёсткий контроль, необходимый в отношении человечества, в своем окончательном виде, однако, не требует никаких особенных технологий: культура концлагерей, массовых геноцидов и т.п. давно сформирована, технологии биологического контроля уже внедрены. Сознание является последним аспектом, который необходимо уничтожить на пути к тотальной власти неорабовладельческого единого государства XXI века. Поэтому современный форсайт образования, включая его внимание к цифровым технологиям, строится именно с целью способствовать уничтожению сознания граждан. Это не столько прогноз, сколько план уничтожения, включающий многочисленные «гринфилды», при помощи которых планируется поддерживать homo officialis в необходимом состоянии полной покорности. Согласно сторонникам глобализации и мондиализации (которой в современном мире отчасти благополучно противостоят «сепаратистские» и иные движения национального возрождения) масштабные инновации в образовании происходят нечасто: якобы, за последнюю тысячу лет их было всего несколько, включая идею прагматичного образования Дж. Дьюи, возникшую в XIX веке [17, с. 4; 30; 31 ]. В этом списке практически не представлены наиболее прогрессивные идеи теоретиков и практиков иных зарубежных и отечественных школ. Современные исследователи, как кажется, даже не слышали о них, сопоставляя образовательные «браунфилды» и «гринфилды» западного образования и выстраивая форсайт на основе часто неоднократно проявивших свою ущербность западных моделей. «Гринфилды» как якобы «новые» образовательные проекты (образовательные стартапы), созданные на новых технологических (цифровых) основаниях в последние годы получили специальное название - «EdTech» [17, c. 3]. В рамках пропаганды «гринфилдов» помимо формирования усеченного понимания мира и 
полного отсутствия внимания учащегося / обучающегося к пониманию себя, превозносится бескультурье, связанное с неуправляемым проникновением в жизнь современного человека цифровых и иных технологий. Опасности «цифровой зависимости» ни сколь не смущают сторонников «гринфилда», напротив: цифровая зависимость как важная часть порабощения сознания человека выступает важной целью современного образования. Это образование нравственно, содержательно и формально опустошённойе и деформированное. Если бы мы говорили о форсайте образования, направленного на развитие личности, Homo moralis, то образовательный форсайт должен был бы учитывать и опираться не только на деструктивные псевдо-инновации, но и на «джокеры» зарубежных и отечественных достижений в педагогике (обучении и воспитании). Такие достижения используются во всем мире в наиболее передовых моделях образования в странах посткапитализма: там, где произвол ТНК и, в частности, транснациональных банков, ограничен, ценностью являются социальное служение и забота о человеке. В России и многих иных странах бывшего СССР (Союза Советских Социалистических Республик), также как и в иных странах «третьего мира», население которого готовится к «служебному» способу существования, ТНК ведут бесконтрольную «хозяйственную» деятельность, ценностью является нажива и власть наживы. Рекламируемое ТНК и работающими в рамках ТНК -заказов специалистами в области «форсайта образования» в России и иных странах бывшего СССР, образование, направляемое идеями Дж.Дьюи, его предшественников и его последователей [30; 31], выступает способом возвращения образования к доуниверситетскому способу /уровню обучения и даже к доурочной системе образования. По меркам официальной истории это возврат не просто в ранее Средневековье, но и в гораздо более ранние века: Ното consúmens, сформированный усилиями «дикого капитализма» конца XX века и начала нынешнего века в этих странах должен быть доведен до уровня Homo officialis [15]. Например, превращением программ обучения высшего образования в высшее профессиональное образование, содержательным опустошением программ и переводом программ обучения в «дистанционный» и «самостоятельный» формат и т.д. В СССР, и в том исле в России, существовала система ВУЗов и ССУЗов, была система заочного обучения, качественно по уровню отличавшаяся от очного, был выбор. Теперь этого выбора нет: высшее образование как таковое полностью разрушено и заменено его эрзацами, в лучшем случае приближенного к гибриду самообразования и заочного образования. Сокращаются доводятся до состояния профессиональной деформации / деградации штаты, декларируется и поощряется обучение «без отрыва от производства и «повышение квалификации» форсайт предлагает нам начинать торговать своими способностями, знаниями и умениями уже в школе, он также предлагает всю жизнь платить за получение очередной (весьма скоромной и не дающей возможность понимания себя и мира) доли знаний и умений. Массовизация и медиатизация образования, его содержательная и формальная симуляция, фиктивизация, трансформация образовательных учреждений и научных центров в «образовательные предприятия», живущими ради коммерциализации, «монетизации» и коммодификации, говорит о том, что современное образование, благодаря усилиям ТНК и проводящим интересы ТНК государствам, успешно идет в сторону противоположную развитию, Homo moralis остается воспоминанием немногих [5;8]. «Человеческий капитал» понимается как и иной, финансовый и материальный капитал: его можно и нужно рассовать по банкам (промышленным зонам - концлагерям), лишив человека не только самостоятельности, осознания (понимания) себя и мира $[5 ; 8 ; 17]$. Истинный форсайт отличается вовлечением в процесс изучения и создания будущего тех, кто в нём наиболее заинтересован, 
системным, комплексным моделированием и исследованием основных факторов и сил, которые на это будущее влияют и его трансформируют [5; 7; 15]. Он включает их теоретическое переосмысление и интеграцию методов и технологий, а не просто «медиатизацию» [1; 5; 17]. человек - мера вещей: primum vivere. Он не является предметом купли-продажи, несмотря на то, что на этом настаивают современные форсайтпроекты [20].

Современное начальное, среднее высшее образование в странах бывшего СССР, включая Молдову, Украину, Казахстан, Россию и т.д., переживает интенсивный кризис. Оно все больше десакрализуется и коммодифицируется («монетизируется» или «коммерциализируется»), все больше выступает не институтом культуры и развития человека, а институтом формирования «человека служебного». В процессе активной и всесторонней коммодификации, оно превратилось в сферу бизнеса $[6 ; 11 ; 19 ; 21 ; 32]$ : государственная бюрократия, корпорации и предприятия разных уровней активно вмешиваются в процессы образования, стремясь деформировать процессы управления образованием само образование на самом «начальном этапе»: отбор профессиональных, соответствующих определенной организационной культуре кадров переходит в формирование этих кадров, начиная с вузовского и заканчивая средним и начальным образованием. При этом образование превратилось в продажу образовательных услуг, а абитуриент и его семья - в покупателей этих услуг. Будучи таковыми, желая оставаться «валидным» в мире корпоративных запросов, потребители образования выбирают модели и формы образования, которые бы позволяли им встроится в систему «наилучшим образом»: наилучшим для корпорации и, отчасти, для самого себя. Однако, возможностей ориентироваться на «самого себя» в мире стандартизаций и сертификаций остается все меньше времени и места: соответствие или несоответствие стандартам, в том числе стандартам управления, создает новую зону квиринга. В квиры (странные»), а также в члены «маргинальных» сообществ зачисляются те, кто перешел, не соглашаясь с образованием - торговлей. Стандартизация создает разрыв между человеком как более или менее «неповторимой» индивидуальностью, самоуправляемой и активной системой и человеком как членом корпорации, «частью» бизнеса, производства, пассивным «винтиком» системы. Особенно это заметно там, где управление образованием оказывается остается таким же низко концептуализированным, как и было: стратегия современного буржуа и бюрократа, обслуживающего буржуа, заключается в сиюминутном беспрепятственном личном обогащении, преобладании тактических, а не стратегических приоритетов.

Сиюминутность запросов «времени», запросов государства бизнеса конкретной страны эпохи, отрицает стратегии и концепты управления: нужна непосредственная и наставником-консультантом» помогающим обучающемуся научиться добывать знания самостоятельно, тем самым организуя у него способность к образованию через всю жизнь; в традиционном образовании преподавание является важным элементом обучения, но в образовании максимальная прибыль (нажива). Ради наживы продается и покупается все и вся. И как бы не были оптимистичны специалисты, пытающиеся увидеть «хорошее» в торговле знаниями, умениями и ценностям, а также документами о них наличии (об образовании), бюрократ бизнесмен от образования никогда не поставит свои интересы рядом с интересами культуры и человечества.

Современные ожидания по поводу образования как бизнеса хорошо отображает следующая цитата, обнаруживающая целую систему иллюзорных деклараций: 
«В связи с тем, что образование становится бизнес-проиессом, меняются $и$ его черты: основанием для стратегии управления в традиционном образовании является документы, имеющее законодательную основу ..., в образовании как бизнеспроиессе создание стратегии исходит из ситуации запроса на ту или иную образовательную услугу; в традиционном образовании обучение заключается в получении уже существуюших знаний, образование в условиях рынка же ставит задачей сделать обучение ни чем иным как созданием нового знания, при котором обучаемый получает что-то для себя лично из того что он уже умеет делать; в традиционном образовании преподаватель является «знатоком» передающим знания обучающемуся, ...система образования в условиях рынка делает преподавателя «как бизнес прочессе акиент ставится непосредственно на обучение, преподавание становится средством обучения; традичионное образование основано на анализе причинно-следственных связей, т.е. анализе прошльх достижений, при образовании в рыночных условиях направленность обучения становится форсайтом; в традиционном образовании за оиибку обучающемуся следует наказание неудовлетворительной отметкой, в современной рыночной системе образования ошибка поошряется как возможность нахождения нового пути решения той или иной задачи, т.е. поощряется развитие креативного мылиления; в традиционном образовании организация учебного прочесса строго дисииплинирована $u$ регламентирована, в образовании как бизнес проиессе это исходит из учебной ситуации -из проблемь; и наконеи, в традиционном образовании управление образовательной организачией представлено вертикалью власти -иерархией управления, тормозящей развитие организачии в рыночных условиях, образование как услуга требует применения особых бизнес-технологий в управлении -тимбилдинга: командное управление -основа качества и конкурентоспособности организации на рынке образовательных услуг» [24, с. 120].

Поскольку данная цитата кочует из источника в источник, постольку, очевидно, речь идет о некоем программном документе-первоисточнике, задавшем рамку «требуемого» понимания происходящего последние десятилетия тотального развала образования в странах бывшего СССР и иных европейских стран бывшего «социалистического лагеря» (Чехословакия, Румыния, Венгрия, Польша, ГДР, Албания, Болгария, Югославия, и т.д.), так называемого «Второго мира». Этот развал проходил в форме «бархатных революций» (velvet revolution), сопутствующих им «реформ» и «нового этапа развития». «Бархатные, нежные или цветные» революции - как бескровное свержение правящего режима - особый класс революций, руководящую роль в которых играют группы элиты, конкурирующие с той частью элиты, которая примыкает к власти. Цветные революции - это проекты по свержению легитимной власти в странах второго мира (бывший СССР и его союзники) и третьего мира (Ближний Восток, Африка, Азия, Латинская Америка), инициируемые в помощью ряда неоднозначных (как выборы) или трагических (как теракты) событий «меценатами» - ТНК и государствами «Первого мира» с целью ослабления конкурентов и повышения власти, возврата или захвата колоний, заработка на беспорядках, сопутствующим им смертях и военных действиях и т.д.. Организуются как мирное гражданское восстание, комплекс мирных протестов (забастовки, митинги, демонстрации), направленных на принуждение власти к выполнению требований граждан или, при невозможности договориться, смену правящей 'элиты. Примером являются произошедшие в некоторых странах Европы «смены ориентаций», или как «перестройка» с последующим политическим переворотом в СССР/России. Цветные революции иногда противопоставляют «настоящим» переворотам, случавшимся до начала XX века, однако, раздел СССР явился абсолютно 
«настоящим», прошел со сменой идеологии, строя и законов страны, хотя и не привет к непосредственной гибели множества людей. Люди начали гибнуть позже: в течение последних десятилетий в результате «реформ» ушла из жизни половина населения бывшего СССР. Современные перевороты имеют целью перераспределения властных ресурсов и только. Никаких инноваций и, тем более, задач по исправлению ситуаций в этих странах они не предполагают. В результате того, что элита СССР отказалась от своей управляющей роли как геополитического лидера, автоматически произошел переход этих стран под эгиду другого геополитического центра, капиталистического или «Первого мира» $[33 ; 34 ; 35]$. Общая черта таких революций, однако, - их нелегитимность. Обычно называют следующие характеристики таких революций: конфликт легитимности и законности, неправовая передача власти - фактический государственный переворот, поддержанный организацией массового движения с целью придания легитимности (прежде всего - молодежного); смена поколений элиты с отстранением старой партийной номенклатуры; декларация либеральных экономических реформ как альтернатива предшествующей политике; выраженный национализм; ориентация новых политических режимов на Европейский Союз и НАТО, пересмотр отношений с Россией во внутренней и внешней политике. Часто отмечают также, что это - искусственные революции, результат воздействия современных политических технологий, примененных в отношении стран с неустойчивой элитой и слабыми историческими традициями суверенитета. Бархатные революции выражаются в массовых выступлениях, поводом для которых являются якобы имеющие место нарушения демократических процедур. Итогом бархатных революций становится долгосрочное падение производства в стране, ухудшение инвестиционного климата, постоянная ротация элит, правительственная чехарда, сопровождаемая многократным перераспределением и разграблением ресурсов и активов, утрата доверия масс к демократическим процедурам, цинизм, десуверенизация страны, попадание ее в полную зависимость от других государств, от западных грантов и кредитов, от фондов, НГО и НКО, установление в стране режима управляемой демократии. При этом в конце $\mathrm{XX}$ века эти революции произошли сравнительно быстро, почти одномоментно, в соответствии с «принципом домино», по одному и тому же сценарию, что говорит о том, что они были не следствием внутренних социальных противоречий, а результатом вмешательства извне. Поэтому для этих стран реальность стать странами «Третьего мира», весьма высока, как и для России. Это видно на примере показателей образования и науки, здравоохранения и юстиции, промышленности и сельского хозяйства и т.д.: неуклонное и стремительное падение вниз. Так, в результате этих революций многие страны «где-то и когда-то незаметно перескочили с бизнес-образования на образованиебизнес и по какой-то причине решили, что образование «также должно быть ориентировано на рыночные процессы» [26, с. 195-196]. Жонглирование словами стало не просто развлечением, а массовым повальным занятием «реформ» образования в конце ХХ - начале XXI века. В России существует «не рынок, а... «муляж рынка», представляющий собой «извращенную рыночную экономику, отдельные рынки не сливаются, а существуют независимо друг от друга и организуются лишь в интересах предпринимателей» [2, с. 4].

Т. Карл и П. Шмиттер в конце XX века описали результаты «реформ» и «революций», организуемых ТНК: «Никогда не утверждалось, что во всех странах, где меняются лидеры, либерализуются отдельные аспекты политической жизни, принимаются новые конституции и начинают проводиться альтернативные выборы, происходит смена режима... Никто никогда не утверждал, что режимный транзит всегда означает переход к демократии. Напротив, в литературе, посвященной исследованию различных типов 
транзита, ясно говорится, что даже после начала режимных изменений траектории развития могут быть самыми разными: одни страны будут двигаться к консолидации демократии, другие — к некой новой форме авторитарного правления» [34]. Важным моментом является то, что ни одна «цветная революция» не становится успешной в итоге, она лишь создает перманентную буферную зону нестабильности в регионе у границ стран [36]. И эта нестабильность оплачивается жизнями и судьбами людей и культуры. В итоге, например, в настоящее время параллельно существует не университетское образование и наука, а несколько наук и образований: часть из низ, как очевидно, - муляжи, симулякры и того, и другого. При этом богатство культуры, богатство мира, его тайны теряют интерес: интерес вызывает то, что приносит прибыль. Тайны интересны постольку, поскольку позволяют сохранять status quo или наращивать власть, привлекательность, авторитетность (социальные и человеческие капталы, подлежащие «конвертации» продаже). Сошлемся также на слова И. Грачева: «Одна из причин, почему знания не превращаются в товар, в инновации, заключается в том, что внутренний рынок потребления знаний в России чрезвычайно невелик. Если оценивать в целом, то рынок инноваций окажется очень скромным - всего около 10 млрд долларов. Для того чтобы инвестировать в эту отрасль 50-60 млрд долларов (то есть сопоставимо с сырьевыми отраслями) надо продавать товаров на порядок больше - на 500 млрд долларов. Даже если рассчитывать на меньший объем продаж (в пределах 200 млрд), то и таких рынков внутри страны пока что нет. И долго еще не будет» [10, с. 13]. Да и не нужно: деньги есть, рабы есть, культура «нравственная экономика и политика», креативная, а сервильная цели школы и вуза, науки и инноваций, - уже излишни. «Образовательный прорыв» оборачивается своим истинным лицом: «образовательный обрыв». Уровень образования падает составляет 4-2,5 \% (!) от уровня СССР в середине XX века. Не лучше дело в самом Евросоюзе (Англии) а также США, с которым мы так стремимся интегрироваться и на которых хотим походить: «Пока профессора трансформируются в менеджеров, студентов превращают в потребителей... Заслуги науки равны тому, сколько денег вы можете на неё собрать, а образованный студент теперь по определению тот, кто способен найти работу» [16, с. 23-24]. Как отмечает Ю.П. Савельев, основное препятствие модернизации (в том числе и в инновационной деятельности) в следующем: «По сути дела все поправки к законам (в сфере образования - А.М.), и в том числе касающимся автономных образовательных учреждений, были направлены на тотальную коммерциализацию учебного процесса и превращение системы образования из основной отрасли, которой занимается государство, в сферу услуг. Таким образом, образование в нашей стране превратилось из объекта в субъект» $[22$, с. 3]. К сожалению, в современном мире многие страны идут по этому пути. «То, что студенты нередко воспринимают себя и (или) своих родителей потребителями, - далеко не заблуждение, поскольку современный Университет все больше превращается из идеологического орудия государства в бюрократически организованную и относительно автономную потребительски ориентированную корпорацию» [21, с. 25]. Превращение образования в «образовательную услугу» - это деформация сути университетской деятельности. «Университеты и институты высшего образования подчиняются отныне, - пишет Ж.-Ф. Лиотар, - требованию формирования компетенций, а не идеалов... Передача знаний не выглядит более как то, что призвано формировать элиту, способную вести нацию к освобождению, но поставляет системе игроков, способных обеспечить надлежащее исполнение роли на практических постах, которые требуются институтам» [19, с. 118].

Пропаганда «руин» строится на риторике «самореализации» и «заботы о человеке», но на самом деле не имеет к ним никакого отношения. М. Стронг пишет, что 
«Человечество должно начать относиться к образованию, как к нормальной рыночной услуге... смысл образования в том, чтобы взять молодого человека и подготовить его к жизни. Ни в коем случае не говорить ему, что делать, а просто дать ему навыки включая и академические, - которые позволят ему быть успешным, счастливым и востребованным в нынешнем, а не прошлом, столетии» [15, с. 1]. Казалось бы, вполне здравая позиция. Позиция, которая, оказывается, ведет нас к любимому американскому слогану «лучший в» (вариант - «сделавший сам себя» - best of the world/ self-made man): «Чтобы реализоваться, человеку нужно блистать в чем-то - не более того... человек должен понять, что у него выходит лучше всего, и найти какой-то спрос на свою деятельность $[15$, с. 1]. Оказывается, вся эта «самореализация» нужна только для поиска ниши и удовлетворения спроса иных потребителей. Ничто иное в «блистании» ценности не имеет: «красивая жизнь» стоит дорого, но если не замечать отсутствия человеческого, культурного смысла такой «самореализации», если не замечать, что пропаганда уникальности касается именно уникальных ситуаций людей, то можно попробовать «взять от жизни все». Не взирая на то, что взять не можешь, не нуждаешься и не понимаешь что берёшь и зачем. Слово «дать» (служить, дарить, творить, здесь явно неуместно, поскольку означает труд и развитие вне ниши, вне «блеска». Однако, как сформулировал еще О. де Бальзак, блеск сопутствует с нищетой, а также - осуществляется в рамках отношений купли и продажи («блеск и нищета - это блеск и нищета куртизанок») [4]. Замечание о том, что «Один из самых важных навыков в XXI веке - это нахождение новых рыночных ниш. Каждый человек должен быть хотя бы немножко предпринимателем», совсем не соответствует следующему утверждению: «Наша задача - переключиться со внешней мотивации и внешних стандартов на внутреннюю мотивацию и внутренние стандарты» [23, с.1]. Не вполне ясно, каким образом «внешний блеск» может стать внутренним стандартом: разве что в результате маркетинговых ходов, хорошо описанных тем же О. де Бальзаком и активно развиваемых транснациональными корпорациями. И уж наверняка развиваемых - не в целях дать, облагодетельствовать жаждущего «блеска» потребителя. Однако, М. Стронг очень хорошо чувствует парадокс: «Большинство людей, которые верят в прогрессивные образовательные методики, не верят в рыночную экономику, а большинство людей, которые верят в рынки, отказываются допускать, что возможны принципиально иные, лучшие системы образования» [23, с.1], хотя не может его объяснить. Объясняет ее другая сторона его же высказываний: чтение и окружение себя людьми, которые обладают знаниями в разных областях, вполне способно заменить годы, проведенные за партой, в школе и вузе. Мы можем учиться по-разному, но формализм, в том числе превращение образования в бизнес и торговлю, проблему не решают, а ухудшают. Можно не любить что-то в образовании как процессе ретрансляцию культуры, но ретрансляцию этой культуры отменить нельзя. И обучения у людей, знающих о мире больше желающего блистать потребителя - тоже. Ребенок без взрослого вырастает Маугли. Ребенок в среде торгующих собой и миром взрослых - Иудой. Отказ от нравственных норм, от запретов предписаний культуры достижение состояний неидентифицируемых, не рефлексируемых как таковых подлости и одичания - тот феномен, который мы уже отмечали, -неизменные атрибуты «рыночного» образования. И одичание подлости, как мы видим из сымпровизированного нами «диалога» М. Стронга и Т. Иглтона, начинается не с учеников. С учителей. С администрации. С общества и государства. Некоторые страны - Швеция, Финляндия, Голландия - понимают и изъяны, и достоинства всеобщего образования и пытаются сделать систему более гибкой поднимают планку требований к культуре отношений в школе, к методикам образования воспитания. У них получается - новое чудо. 
Большинство же государств корпораций по всему миру монополизировали право назначать содержание, формы, размеры и «стоимость» образования: сведя само образование к возможно «большему минимуму», а его оплату - к максимуму [16; 23]. Описывая «университет в руинах», Б. Ридингс отмечает: «Университет ... становится транснациональной бюрократической корпорацией, либо связанной с транснациональными инстанциями управления, такими как Европейский Союз, либо функционирующей независимо по аналогии с транснациональной компанией» [21, с. 12]. Это - означает конец автономии университета как корпорации преподавателей и студентов. Превращение университета в корпорацию по продаже «образовательных услуг» [10, с. 13-14] влечет рад последствий: ориентация учебных планов форм образования на вкусы потребителя, борьба университетов за рынок с помощью рейтингов и рекламных кампаний; оценивание преподавателей студентами, а также сокращение объема предоставляемых студентам знаний во имя последующей его дополнительной продажи под вывеской «непрерывного образования»; сокращение времени обучения, и навязывание ему «логики учета» [12, с. 202, 211], борьба университетов за исследовательские гранты, основные шансы в этой борьбе имеют быстро высоко окупаемые проекты т.д. $[6 ; 10 ; 12]$. Этому часто можно противопоставить лишь «отдельные паллиативные меры», способные немного отсрочить окончательную гибель университета: постмодернисткая методология субъективистского препарирования знания и процессов его общественной трансляции («дереференциализация», «деконструкция», «шизоанализ»), которая поддерживает иллюзию свободного духовного творчества, но реально завершает процесс разложения науки и образования под управлением транснациональныго капитала, снявшего с себя какие-бы то ни было социальные и культурные обязательства.

Тема «кризиса» и «конца» университета, проблемы взаимодействия университета и власти (бизнеса) и утраты университетом духа свободы, изменения сути «идеи университета» как множественного феномена, а также проблемы массовизации образования как проявления «восстания масс» и необходимости формирования «нравственных специалистов», то есть личностей, способных противостоять натиску масс, популярны в течение всего XX века и ранее (работы Ф. Ницше, Х. Ортеги-и-Гассета, М. Вебера, Э. Дюркгейма, К. Ясперса, А.Н. Уайтхеда, В. Гумбольдта, Дж. Ньюмена, Ж.-Ф. Лиотара, Б. Ридингса [18; 19; 21].

В России и мире превозносятся идеи Дж. Дьюи и иных ученых, легко заменяющих «служение» на «обслуживание». Опасность этой «игры слов» иллюстрирует Э. Дюркгейм, который связывал с развитием специализации образования возникновение новой нравственности, когда «все будут сотрудничать для блага всех и каждого» [13, с. 378]. «Новая нравственность» оказалась старой безнравственностью. К. Манхейм на примере фашизма описал плоды деятельности больших и маленьких «вождей»: специализация, нейтрализующая интерес к реальным проблемам и путям их разрешения и терпимость (объективность), настаивающая на важности развитии способностей «блистать», способствует на самом деле подавлению сознания / рефлексии: «нельзя спасти автономию личности, пренебрегая анализом социальных условий, в которых человек должен жить и выжить» [19, с. 480].

П.Г. Щедровицкий пишет: «Личностное и индивидуальное развитие не должно отождествляться с идеями индивидуализированной подготовки и обучения. Это совершенно разные идеи и программы... В идее индивидуализированного обучения кумулирована программа целевой и жестко ориентированной подготовки человека к функциональным обязанностям во внеобразовательных системах; эта идея воплощает в 
себе все тенденции специализации подготовки, вызванные усложнением и дифференциацией современного технологического производства» [27, с. 14]. «Логика достижения целей противопоставляется логике расширения жизненных шансов... Образование, в отличие от подготовки кадров, бесцельно, в том смысле, что оно не ориентируется ни на какие внешние системы, как на источник формирования заказа или требований к результатам обучения или воспитания» [27, с. 133-134]. Аналогично понимает «заботы» либералов (буржуа) и М. Шелер: «Образование - это не «учебная подготовка к чему-то», к профессии, специальности, ко всякого рода производительности, и уж тем более образование существует не ради такой учебной подготовки. Наоборот, всякая учебная подготовка «к чему-то» существует для образования, лишенного всяких внешних «целей» - для самого благообразно сформированного человека» [25, с. 64]. При этом «образование выводит человека «за пределы того, что человек непосредственно знает и постигает. Оно состоит в том, чтобы научиться придавать значение другому, находить обобщенные точки зрения, чтобы «воспринимать объективное в его свободе и без своекорыстных интересов» [9, с. 55].

Заключение. Человечество не раз сталкивалось с серьезными переменами информационных потоков и необходимостью перемен управления ими, особенно в образовании. Современный этап - ничем особенно не отличается: как и в прежние века, человечество ищет истину, даже если ему кажется, что найти ее и передать ее невозможно. Университет как место диалога поколений, место диалога человека и культуры, будет жить. Будут меняться его формы и приоритеты, но основные его функции, не исчезнут: людям всегда будет чем поделиться с другими, что передать другим, что открыть - в себе и мире. Капитализм и его интересы не вечны, без него человечество существовало и будет существовать. Вечна культура, без которой человечество не существует. Поэтому образование, как бы оно не стремилось удовлетворить «насущные нужды» современного бизнеса, работало работает не над созданием «человека служебного», не над созданием «квалифицированного потребителя», «man serving», а над развитием человека как личности, как субъекта культуры и собственной жизни [3].

\section{Литература}

1. Арпентьева М.Р. Гуманистика: цели «роботоустойчивого образования» // Сетевое взаимодействие как условие формирования нового качества профессионального образования. Сборник материалов III Всероссийской (с международным участием) научно-практической конференции. Борисоглебск, 5 апреля 2018 г. - Воронеж: Ритм, 2018. - С.5-10.

2. Айвазов А. Не«рента»бельное хозяйство // Литературная газета. - 2007. - 18-24 апреля. № 16. - С. 4.

3. Арпентьева М.Р., Меньшиков П.В. Дидактическая коммуникация: умение учиться и умение учить / Под ред. М.Р. Арпентьевой. Калуга: КГУ, 2017. - 354c.

4. Бальзак де О. Блеск и нищета куртизанок // Бальзак де О. Собрание сочинений. В 15 томах. Т. 9. Человеческая комедия. Москва: Художественная литература, 1954. - 320с.

5. Барбер М., Доннелли К., Ризви С. Накануне схода лавины // Вопросы образования. - 2013. - № 3. - С. 152-231.

6. Бок Д. Плюсы и минусы коммерциализации к // Отечественные записки, 2003. №6(14) . - С. 56-72.

7. Будущее образования: глобальная повестка. Доклад, подгот. АСИ Сколково и Сколтехом [Электр. pec.] // URL: edu2035.org/pdf/GEF.Agenda_ru.pdf (дата обращения 10.09.2017)

8. Буров В.В. Вызов 2035.- М.: Олимп-Бизнес, 2016. - $256 \mathrm{c}$. 
9. Гадамер Х.-Г. Истина и метод: Основы философской герменевтики. - Москва: Прогресс, 1988. - 704c.

10. Грачев И. Хорошо забытое новое // Литературная газета. 2007. - 8-14 августа, №32. - C. 13.

11. Джерджен К. Дж. Социальное конструирование и педагогическая практика // Образовательные практики: амплификация маргинальности /Под. ред. А. А. Забирко. Минск.: Технопринт, 2000. С. 74-101.

12. Долженко О. Очерки по философии образования. - Москва: Промо-Медиа, 1995. C. 206-211.

13. Дюркгейм Э. О разделении общественного труда. Метод социологии / Э. Дюркгейм. - Москва: Наука, 1991. - 575с.

14. Евзрезов Д. В., Майер Б. О. Форсайт и российское образование // Проф. образование в совр. мире. - 2013. - № 3(10). - С. 17-28.

15. Жукова Г.К. Сага о форсайте или об идолах Global Education ... // VIII заседание Молод. дискусс. клуба РИСИ «Иностранное влияние на сферу образования в России» СПб.: РИАЦ, 30.09.2016. URL: http://katyusha.org/view?id=3365 (дата обращения 10.09.2017)

16. Иглтон Т. Медленная смерть университета // Совет ректоров. - Москва: ООО «Образование 3000» (Москва). - 2015. - №4. - С. 19-26.

17. Крюков С.В. Форсайт // Пространство экономики. 2010. - №3-2. - С. 7-17.

18. Лиотар Ж.-Ф. Состояние постмодерна. - Санкт-Петербург: Алетейя, 1998. - С. 118 119.

19. Манхейм К. Диагноз нашего времени. - Москва, Юрист, 1994. - 538с.

20. Песков Д. и др. Что такое форсайт образования [Электр. Рес.] // Наука и технологии России. — URL: http://www.strf.ru/material.aspx? CatalogId=354\&d_no=72965\#.WcgOQLJJbIV (дата обращения 10.09.2017)

21. Ридингс, Б. Университет в руинах. - Москва: Высшая школа экономики, 2010. $304 c$.

22. Савельев Ю.П. Все граждане России в XXI веке должны иметь высшее образование // Санкт-Петербургский вестник высшей школы, 2007. - № январь-февраль. - С. 3.

23. Стронг М. Злокачественное образование // Искусство жить красиво. - 2014. - 12 июля, №1. - URL: https://esquire.ru/archive/5497-michael-strong/ (дата обращения 15.03.2018)

24. Чайчук, Е.О. Проблемы управления образованием как бизнес-процессом // Модернизация хозяйственного механизма сквозь призму экономических, правовых, социальных и инженерных подходов : сборник материалов IX Международной научнопрактической конференции, 30 ноября 2016 г. Минск : Белорусский национальный технический университет, 2016. С. 195-196.

25. Шелер М. Формы знания и образование // Человек, 1992. - №5. С. 63-75.

26. Шпилевая И.Е., Анисимова Т.С. Бизнес-технологии в образовании // Научнометодический электронный журнал «Концепт», 2015. - S7. C. 116-120. URL: http://ekoncept.ru/2015/75128.htm (дата обращения 15.03.2018)

27. Щедровицкий П.Г. Очерки по философии образования (статьи и лекции) / П.Г. Щедровицкий. - Москва: «Эксперимент», 1993. - 154c.

28. Эпоха «гринфилда» в образовании // Исследование Сколково (SEDeC), сентябрь 2013. URL: skolkovo.ru/public/media/documents/ research/education_10_10_13.pdf (дата обращения 10.09.2017)

29. Aoun J. E. Robot-Proof: Higher Education in the Age of Artificial Intelligence. - New York, London: MIT Press, 2017. 216 p.

30. Cubberly E.P., Public School Administration: A Statement of the Fundamental Principles Underlying the Organization and Administration of Public Education. New York: Nabu Press. 1905/ 2014. $-546 \mathrm{p}$.

31. Dewey J. My Pedagogical Creed. New York: Forgotten Books, 1897/2017. 50p..

32. Erasmus + Итоги программы Tempus и новая программа Erasmus + Москва: Erasmus + , Национальный Национальный офис Erasmus ${ }^{+}$в России, 2016. 38 с. URL: 
http://www.ric.vsu.ru/UserFiles/File/201505/20150512/20150512

_Anna_Muraveva.pdf _ (дата обращения 15.03.2018)

33. Ash T.G. We the People: The Revolution of '89, Witnessed in Warsaw, Budapest, Berlin and Prague . - Cambridge, Penguin UK, $1990.160 \mathrm{p}$.

34. Karl T., Schmitter P. Models of Transition in Latin America, Southern and Eastern Europe // Intern. Social Science J. 1991. № 43. P. 269-284.

35. Ross C. The Leaderless Revolution: How Ordinary People Will Take Power and Change Politics in the 21st Centuryю - New York City: Simon \& Schuster, The Financial Times Limited 2018. $400 \mathrm{p}$.

36. Sebetsyen, V. Revolution 1989: The Fall of the Soviet Empire. New York City: Pantheon Books, 2009; Vintage, 2010. 498 p. 